\title{
ARQUITETURAS DA HABILITAÇÃO PROFISSIONAL PARA A DOCÊNCIA E AS BASES DA FORMAÇÃO E PROFISSIONALIZAÇÃO EM CONTEXTO EUROPEU
}

\author{
HENRIQUE MANUEL PEREIRA RAMALHO \\ ORCID: https://orcid.org/0000-0002-5512-1278
}

IInstituto Politécnico deViseu (IPV), Escola Superior de Educação (ESEV), Departamento de Psicologia e Ciências da Educação, Viseu, Portugal.

RESUMO: Neste texto, desenvolve-se uma análise e compreensão das bases da formação e profissionalização docentes em perspetiva comparada, convocando, em particular, três contextos europeus: Portugal, Espanha e França. Metodologicamente, procedemos a uma análise de conteúdo sistemática de legislação e documentação oficial conexa à estruturação dos processos de formação, profissionalização e habilitação docentes, em vigor em vários Estados subscritores da Declaração de Bolonha. Desenvolvemos uma sistematização de procedimentos do tipo temático categorial (Bardin, 1995), obedecendo a uma metodologia de análise de inferência não frequencial, alinhada com um exercício de agrupamento de significações da mensagem, recorrendo a um processo de enumeração de "referências específicas" empiricamente relevantes (Almeida \& Pinto, 1995). Em conclusão, aventamos a hipótese da institucionalização de perfis de desempenho e de quadros normativos de habilitação para a docência dotados de uma convergência filosófico-política de alta intensidade, com propósitos de harmonização e, até, de hegemonização de uma cultura de formação e profissionalização docentes.

Palavras-chave: Perfis de desempenho. Habilitação para a docência. Profissionalização. Profissão docente. Declaração de Bolonha.

Henrique M. P. Ramalho - Doutorado em Ciências da Educação, na especialidade de Organização e Administração Escolar Professor Adjunto de nomeação definitiva, do Departamento de Psicologia e Ciências da Educação, da Escola Superior de Educação (ESEV), do Instituto Politécnico de Viseu (IPV), Portugal. Grupo de Pesquisa CI\&DETS - Centro de Estudos em Educação, Tecnologias e Saúde - unidade pluridisciplinar de gestão da investigação do IPV. E-mail:<hpramalho@esev.ipv.pt> 


\section{ARCHITECTURES OF PROFESSIONAL ENABLING FOR TEACHING AND THE BASIS OF TRAINING AND PROFESSIONALISM IN A EUROPEAN CONTEXT}

ABSTRACT: This text develops an analysis and understanding of the bases of teacher training and professionalism in a comparative perspective, calling in particular three European contexts: Portugal, Spain and France. Methodologically, we proceed to a systematic content analysis of legislation and official documentation related to the structuring of the processes of training, professionalization and educational qualification in force in several States subscribing to the Bologna Declaration. We have developed a systematization of categorical thematic procedures (Bardin, 1995), following a non-frequency inference analysis methodology, aligned with an exercise in grouping meanings of the message, using a process of enumeration of empirically relevant "specific references" (Almeida \& Pinto, 1995). Concluding, we hypothesized the institutionalization of performance profiles and normative frameworks for teaching with a highlevel philosophical-political convergence, with the purpose of harmonizing and even hegemonizing a culture of teacher training and professionalism.

Keywords: Performance profiles. Qualification for teaching. Professionalization. Teaching profession. Bologna Declaration.

\section{INTRODUÇÃO}

Este trabalho concretiza uma análise e interpretação à cartografia da formação e profissionalização de professores e educadores (em sentido genérico), balizada pelos sentidos e significados dados aos conceitos de perfil de desempenho e habilitação para a docência em contexto europeu, prosseguindo na linha de quatro eixos fundamentais: i) o enquadramento dado pelas fronteiras filosófico-políticas da contextualização social (e, necessariamente, sociológica) das funções, dos saberes, dos processos de legitimação, institucionalização e regulação da profissão, de que decorre, também, o estatuto socioprofissional dos docentes. ii) a (in)definição da filosofia e das políticas que, numa perspectiva de abertura de convergência, têm orientado a produção dos discursos oficiais, mais ou menos reformistas, sobre o modo como deve ser formado e para quê o professor exerce a sua atividade (cf. Ponte, 2005); iii) articuladamente, procura-se analisar e interpretar a formação de professores à luz do paradigma da aprendizagem ao longo 
da vida; iv) o modo como as arquiteturas de formação de professores de diferentes países da "zona Bolonha" se (des)articulam com quadros de competências definidos em linha com a normalização dos perfis de desempenho profissional (Serralheiro, [org.], 2005).

Começamos por dirimir argumentos teóricos e concetuais (como primeiro campo de análise) em torno das fronteiras filosóficopolíticas da contextualização normativa das funções, dos saberes, dos processos de legitimação, institucionalização e regulação da profissão docente, de que decorrem, necessariamente, os sentidos dados a uma política europeia de convergência na produção dos discursos oficiais, mais ou menos reformistas, sobre o modo como deve ser formado e para quê o professor exerce a sua atividade, à luz do paradigma da aprendizagem ao longo da vida. Na última fase, culminamos o nosso ensaio com a análise do modo como as arquiteturas de formação de professores de diferentes países da "zona Bolonha" (Espanha, França e Portugal) se (des)articulam com quadros de competências definidos em linha com a normalização dos perfis de desempenho profissional.

Surge com especial destaque o esquema de regulação da profissão docente inscrita numa agenda de europeização normalizada e de feição transnacional, pondo em especial destaque o papel da União Europeia (UE) e respetivo órgão executivo, conectado à agenda de Bolonha, enquanto unidade de comando da Área Europeia de Ensino Superior (AEES), em que a formação e profissionalização docentes se inscrevem. A propósito, chama-se a atenção para as inequívocas posições reformistas da educação, do tipo voluntarista, dos Estados-Membros, levadas a cabo, invariavelmente, em linha com a prerrogativa do topdown, tendo como centro hiperburocrático, a Comissão Europeia (CE). A grande narrativa de base, recorrendo ao Método Aberto de Coordenação, cuja governação assume carácter voluntarista de cooperação intergovernamental na UE, circunstancia-se no que apelidamos por ideologia das competências (cf. Comissão Europeia, 2016), amplamente sedeada na linha do desenvolvimento de políticas práticas centradas numa neoescolarização da sociedade europeia e na neopedagogização dos problemas de competitividade e de produtividade da União, numa clara apologia à planificação de uma Europa, economicamente, mais competitiva. 


\section{PERFIS DE DESEMPENHO DE PROFESSORES/EDUCADORES E HABILITAÇÃO PARA A DOCÊNCIA: SOBRE AS FUNÇÕES, OS SABERES E OS PROCESSOS DE LEGITIMAÇÃO E REGULAÇÃO DA PROFISSÃO}

A nossa primeira consideração leva-nos a envolver os mecanismos de normalização dos perfis de desempenho e da habilitação para a docência (cf. Serralheiro, [org.], 2005) da zona de Bolonha na agenda mais recente da regulação das políticas públicas, entendendo-se, por exemplo, como sinónimo de

\footnotetext{
Diferentes arranjos institucionais, definidos, promovidos ou autorizados pelo Estado, tais como as regras e leis, o poder e as competências delegadas a autoridades locais, às hierarquias dos estabelecimentos escolares ou às organizações profissionais, os dispositivos de controle e de avaliação, mas também os dispositivos de coordenação pelo jogo do mercado, do quase mercado, constituem então os modos de regulação do sistema. Eles contribuem para coordenar e orientar a ação dos estabelecimentos, dos profissionais, das famílias na distribuição de recursos e interdições (Maroy, 2005, p. 1).
}

$\mathrm{Na}$ linha de análise que traçamos em torno deste primeiro eixo de análise, começa a ser vulgar associar o efeito de regulação ao vulto ideológico da New Public Management (Lessard, 2006), decorrente de um crescente interesse que organismos internacionais, como o Banco Mundial (BM), o Fundo Monetário Internacional (FMI), a Organização para a Cooperação e Desenvolvimento Económico (OCDE), a Comissão Europeia (CE) e até a Organização Mundial do Comércio (OMC), começam a manifestar em torno do efeito utilitário da escolarização da sociedade (cf. Laval, 2002), com um claro propósito em prolongar esse efeito de escolarização em processos difusos de aprendizagem ao longo da vida, no quadro de uma agenda globalmente estruturada para a educação (Dale, 2000; Antunes, 2004).

Destacamos, particularmente, o papel da CE que se tem vindo a vincar por meio de algumas iniciativas importantes: i) o Programa Educação \& Formação 2010 (Comissão Europeia, 2002); ii) o documento Principios Comuns Europeus para as Competências e Qualificações dos Professores (European Comission, n.d.); iii) o Quadro Europeu de Qualificações para a Aprendizagem ao Longo da Vida (Comunidades Europeias, 2009); iv) o Processo de Bolonha. ${ }^{1}$ E com recurso, por exemplo, a estas iniciativas que se tem vindo a constituir o formato da regulação da qualidade das formações fortemente dependentes de processos de acreditação nacionais e comunitários, tomados como base para o reconhecimento comum e convergente dos diplomas (Antunes, 2005), culminando 
com a elaboração de um quadro de princípios europeus comuns para as competências e qualificações dos professores (European Commission, n.d.). Mais adiante, o documento de trabalho Repensar a Educação - Investir nas competências para melhores resultados socioeconómicos (Comissão Europeia, 2012) veio dar orientações mais precisas sobre os princípios que deveriam suportar as competências e as ações de melhoria da formação de professores e educadores a incrementar nos diferentes Estados-Membros da UE, prevendo, por exemplo, um novo quadro de competências dos professores e educadores (comuns a todas as escolas grupos etários, contextos e disciplinas), a reformulação dos sistemas de recrutamento, a garantia contínua de apoio ao início de carreira, a análise sistemática do desempenho dos professores no decorrer da sua carreira profissional.

Propriamente, o Processo de Bolonha vem reforçar as anteriores orientações e tendências de regulação, sendo-lhe muito próprio um efeito de deslocalização das arenas de debate democrático sobre a formação de professores e educadores, sendo essas arenas substituídas por mecanismos e estruturas tecnocráticos induzidos pela crença no primado da ação especializada de técnicos, peritos, avaliadores institucionais e grupos de trabalho a quem estão associadas ações de avaliação externa e monitorização transnacional (cf. Lima; Azevedo \& Catani, 2008).

No emolumento mercantilista de Bolonha, eis que surge um vinco absolutamente neoliberal: a garantia da qualidade, pois que a um sistema europeu de ensino superior deverá, numa lógica claramente empresarial, estar conectado um sistema europeu transacional de garantia da qualidade que preconize tal incremento. Para o efeito, foi criado o European Quality Assurance Register for Higher Education (ENQA, 2015), cuja reprodução institucional é concretizada pelas diferentes agências nacionais ${ }^{2}$ sujeitas a processos de metaacreditação produtores de standards que deverão ser aplicados a todas as instituições de educação superior e a todas as agências de avaliação nacionais (cf. Lima; Azevedo \& Catani, 2008). Congruentemente,

[...] as estruturas e mecanismos internos de garantia da qualidade deverão constituir uma primeira linha, fundamental, de intervenção nos processos de avaliação, com o objetivo último de promover a interiorização de uma cultura de qualidade que permeie todas as atividades desenvolvidas no interior da instituição. [...] O exposto [...] não invalida a importância da avaliação externa, que é igualmente não só necessária, como essencial, quer para a validação dos mecanismos de avaliação interna, que deverão ser obrigatoriamente incluídos no escrutínio a ser efetuado pelos avaliadores externos, quer como fonte de informação e um juízo de valor validados de forma independente (Santos, 2011, p. 5). 
Congruentemente, baliza-se a formação inicial de professores pela fronteira ideológica da noção de competência performativa (Chaui, 2014), segundo uma "relação performatizada" burocraticamente estabelecida entre o professor, o aluno e o Sistema (Icle \& Lulkin, 2013, p. 117), ao que corresponde, também, uma instrumentalização dos aspirantes a professores para a reprodução de relações pedagógicas, didáticas e, consequentemente, sociais e culturais inscritas num essencialismo formativo, segundo o qual a adaptação ao Sistema se sobrepõe à autonomização profissional:

[...] se estipula perfeitamente tudo o que deve fazer o professor passo a passo ou, em sua carência, os textos e manuais didáticos que enumeram o repertório de atividades que professores e alunos devem fazer etc. Tudo isso reflete o espírito de racionalização tecnológica do ensino, na qual o docente vê sua função reduzida ao cumprimento de prescrições externamente determinadas, perdendo de vista $O$ conjunto e o controle sobre sua tarefa (Contreras, 2012, pp. 40-41).

Sintetizando, eis um horizonte explícito do quadro de funções da formação docente, sendo acoplado ao modelo utilitarista/ produtivista (Antunes, 2007) de resultados a curto prazo, constituindose numa "nova ortodoxia educacional" (Hargreaves et al., 2002, p. 13) suportada por uma reedição dos processos de difusão e enaltecimento das competências com recurso ao conceito de qualificação estritamente vinculado à noção de posto de trabalho e, portanto, às rígidas prescrições de funções e competências e perfis profissionais que atualizam a ação docente no quadro das novas relações de produção escolar. Ou seja, a profissionalização mostra-se amplamente dependente da difusão utilitarista e produtivista da noção de competência profissional (cf. Shiroma, 2003), ocorrendo, com grande probabilidade, uma indigência da noção de saber docente em prol de uma hipervalorização da epistemologia da prática de um docente "treinado" para saber o como agir, cujo saber se encontra, normativamente, sedimentado por programas curriculares pré-estabelecidos, correspondendo a uma compreensão da formação de professores e educadores do tipo pragmático e praticista, com o necessário desenvolvimento ao longo da sua vida profissional (cf. Comisión Europea, 2015).

\section{A FORMAÇÃO DE PROFESSORES À LUZ DA AGENDA DE BOLONHA E DO PARADIGMA DA APRENDIZAGEM AO LONGO DA VIDA: O MODO COMO E PARA QUÊ O PROFESSOR/ EDUCADOR DEVE SER FORMADO}

Mais do que nunca, encontramo-nos conectados à ideia de 
que uma melhor e mais adaptada qualificação docente deverá ser suportada, de forma muito privilegiada, por uma formação marcada por processos de aprendizagem ao longo da vida, em linha com um quadro de referência europeu de Competências Essenciais para a Aprendizagem ao Longo da Vida (European Comission, 2000; Comissão Europeia, 2007). Congruentemente, a tal parece corresponder um modo invariável de, política e ideologicamente, compreender e racionalizar a profissão docente políticas (cf. Simão; Santos \& Costa, 2005), não dando garantias de uma efetiva superação do professor e educador cujo perfil profissional se mantém sob o jugo pragmático e instrumental da execução conforme ao que lhe ao que se espera que lhe seja ensinado na sua formação.

Tal processo progressivo de racionalização da formação de professores eeducadores parece continuarassociadoàinstitucionalização de uma formação que garanta a certeza e a previsibilidade da ação docente, enquanto unidades administráveis do Sistema, em linha com um já clássico "[...] mimetismo em relação aos modelos de análise dominantes no mundo económico e empresarial” (Nóvoa, 1991, p. 63). Algo que, inclusivamente, é esclarecido no sentido em que "Há que centrar esforços no desenvolvimento de competências transversais [...] em particular as competências empresariais ..." (Comissão Europeia, 2012, pp. 3-4), aventando o mesmo documento que

A Europa só conseguirá retomar a via do crescimento através de uma melhor produtividade e de uma mão-de-obra altamente qualificada, desideratos que dependem obrigatoriamente de uma reforma dos sistemas de educação e de formação. [Recorrendo a] plataformas de diálogo a nível da UE, como sejam o método aberto de coordenação no domínio da educação e da formação, o processo de Bolonha para o ensino superior e o processo de Copenhaga para o EFP (Comissão Europeia, 2012, p. 21).

Concretiza-se, nesta linha europeísta da formação de professores e educadores, uma propensão epistemológica para a prática profissional decorrer de um saber aplicado e instrumental, denunciando uma conceção de professor e educador interpretador e aplicador de um saber tecnocraticamente definido na escala da ideologia das competências essenciais sustentada pela recomendação sobre as competênciaschave para a aprendizagem ao longo da vida (European Comission, 2018).

É, aliás, na afirmação ampla do papel da UE na educação e formação naquela linha ideológica, que surge: i) a Estrutura Estratégica - educação e formação 2020, com recurso a iniciativas de gestão da disponibilidade das ditas competências necessárias, como é o caso da 
ESCO - classificação multilingue das competências, competências, qualificações e profissões europeias; ii) ao mesmo tempo, introduz uma terminologia padrão em 25 línguas europeias e categoriza habilidades, competências, qualificaçôes e ocupações relevantes para o mercado de trabalho da EU; iii) concretiza, ainda, uma planificação da educação e treinamento e o Panorama de Competências Europeu - monitorização regular da antecipação de habilidades e a avaliação de habilidades a nivel nacional e europeu, enquanto ponto de acesso central que fornece dados, informações e informações sobre as tendências das habilidades em ocupações e setores a nível nacional e da UE. Estas iniciativas são reforçadas com a adaptação constante da ESCO à realidade do mercado de trabalho, educação e treinamento, com a implementação da ESCO no Europass CV e no EURES - Portal Europeu da Mobilidade do Trabalho. ${ }^{3}$

Neste quadro de orientações políticas da UE, o modo como deve ser formado e para quê o professor exerce a sua atividade (Ponte, 2005) constitui uma preocupação de charneira, destinadas aos responsáveis políticos de cada Estado membro, ainda que difusamente envolvida no quadro mais vasto da política de competências e habilidades consideradas mais úteis para o trabalho e crescimento económico da União, constituindo-se numa das pedras basilares da europeidade (Scott, 2012), precisamente com recurso ao Método Aberto de Cooperação ${ }^{4}$ definido enquanto instrumento na Estratégia de Lisboa de 2000. ${ }^{5}$ Isto, não obstante os perfis produzidos à escala de cada Estado membro serem alvo de uma consolidação mais específica em função da natureza da profissão.

Ainda assim, à escala daquela europeidade, são associadas prerrogativas à formação de professores e educadores comuns às das outras profissões, de forma absolutamente indiferenciada, quando se refere, em concreto, aos déficits de competências na força de trabalho, encaminhando a orientação, a qualificação e a habilitação profissionais para um mercado de trabalho oficialmente definido como volátil, a que se associa a necessidade de desenvolver um conjunto de habilidades básicas (alfabetização, numeracia, língua materna, línguas estrangeiras, ciência e habilidades digitais), de habilidades transversais (capacidade de aprender, ter iniciativa, etc.) e de habilidades empresariais.

Uma das maiores preocupações que se fazem notar ao nível de todas estas orientações passa pela identificação, monitorização e gestão da disponibilidade de habilidades, competências e qualificações necessárias ao crescimento económico, em que ganha 
especial destaque comunicação efetiva entre o mercado de trabalho e o setor de educação e treinamento. A propósito, é significativa a linha estabelecida pela Educação Aberta (EA) ou Recursos Educativos Abertos (REA), ao frisar que

A qualidade da educação assenta numa combinação de diferentes materiais didáticos. Nesta ótica, o acesso alargado aos REA (com o desenvolvimento da sua utilização) deve ser acompanhado de normas claras de qualidade e de mecanismos para avaliar e validar aptidões e competências adquiridas através deste meio (Comissão Europeia, 2012, p. 12).

Neste enquadramento, a Declaração de Bolonha, per se, mantém-se em linha com todas aquelas orientações, sendo convocada como mais um utensílio para a consolidação da estratégia de unificação da UE em torno de um ideário competitivo do tipo intermercantilista, em que a própria Área Europeia de Ensino Superior (AEES) (García Manjón, 2009) - oficialmente lançada na Declaração de BudapesteViena de $2010^{6}$ e consolidada no Comunicado de Bucareste de 2012 - , se constitui num ambiente competitivo ou de um jogo disputado à escala global, surgindo como plataforma estratégica central da afirmação de uma Europa unificada e preparada para a competição por mentes e mercados (Robertson, 2005).

Eis um efeito normativo das metanarrativas europeístas, que procuram o desenvolvimento de políticas práticas centradas numa neoescolarização da sociedade e na neopedagogização dos problemas de competitividade e de produtividade da UE, fazendo depender a resolução desses problemas "da mobilização das vontades individuais e estas da posse de competências adequadas que a escola é chamada a transmitir" (Correia \& Matos, 2001, p. 92). Neste entrecho, o modelo de formação de professores, amplamente centrado no papel de formando, focaliza-se no redesenho organizacional e na redefinição de indivíduo reduzidos à ideia de sujeito aprendente que se "insinua como narrativa totalitária e como instrumento de gestão de uma transição entre o social (enquanto problema) e uma cidade que se constrói como um mercado das oportunidades infinitas" (Correia \& Matos, 2001, p. 92), com o claro propósito de reestruturar dos modelos escolares em função de um plano transnacional de produção de identidades profissionais úteis e de uma excedentarização de mão-deobra adequadamente qualificada (formada e certificada) para aceder ao mercado de trabalho (Correia, 1996; Dubar, 2000; Piotet, 2002). 
Tendo em conta as etapas de análise de conteúdo enunciadas por Laurence Bardin (1995), desenvolvemos uma sistematização de procedimentos do tipo temático categorial, prosseguindo com a definição das respetivas categorias, atendendo, especialmente, à homogeneidade e pertinência qualitativa dos temas adjacentes. Para isso, obedecemos a um procedimento caracteristicamente taxonómico, com recurso a um processo de codificação dos dados brutos inscritos nos documentos selecionados, correspondendo a uma agregação em unidades semânticas de registo ou "unidades de análise" (Almeida \& Pinto, 1995, p. 105), pela execução de "recortes de nível semântico" alinhados com o sentido dado à "noção de tema". Configuramos, assim, uma "análise temática" com recurso a "proposições portador[as] de significações isoláveis" ou "palavras plenas" (Bardin, 1995, p. 104-105), ou a "códigos de definição da situação", que passa por descobrir "núcleos de sentido" (Bogdan \& Biklen, 1994, p. 221-223) com significado para os objetivos analíticos. Para tal, utilizamos a regra da enumeração simetrizada com os critérios da presença e/ou ausência de "núcleos de sentido" (Bogdan \& Biklen, 1994, p. 221) retidos de forma não frequencial e portadores de indicadores com significação relevante. Para o efeito, foi utilizada uma escala relativa de três graus de agregação semântica $(\mathrm{P}+, \mathrm{P}-\mathrm{e} \mathrm{A})$ das referências específicas, no sentido de as enquadrar com o horizonte analítico e inferencial das nossas categorias, em que o valor de significação mais elevado $(\mathrm{P}+)$ sugere uma presença forte ou positiva, o valor inverso ( $\mathrm{P}-)$ indica uma presença mais débil ou negativa de indicadores com significação relevante, e A que aventa uma total ausência e consequente desvalorização de indicadores com significação para a análise da mensagem sistematizada pelo conjunto das nossas categorias e temas adjacentes.

\section{APRESENTAÇÃO, ANÁLISE E DISCUSSÃO DOS DADOS}

\section{Categorização, codificação e sistematização dos dados documentais}

No cômputo global, o nosso corpus textual integrou os seguintes documentos: 
QUADRO 1. Corpus textual

\begin{tabular}{|c|c|}
\hline Documento & Designação \\
\hline D1 (Portugal) & $\begin{array}{l}\text { Decreto-Lei n. } .^{\circ} 240 / 2001 \text { de } 30 \text { de agosto - aprova o perfil } \\
\text { geral de desempenho profissional do educador de infância } \\
\text { e dos professores dos ensinos básico e secundário. }\end{array}$ \\
\hline D2 (Portugal) & $\begin{array}{l}\text { Decreto-Lei n. }{ }^{\circ} 241 / 2001 \text {, de } 30 \text { de agosto - aprova os perfis } \\
\text { específicos de desempenho profissional do educador de } \\
\text { infância e do professor do } 1 .^{\circ} \text { ciclo do ensino básico. }\end{array}$ \\
\hline D3 (Portugal) & $\begin{array}{l}\text { Decreto-Lei n. } 43 / 2007 \text {, de } 22 \text { de fevereiro - aprova o } \\
\text { regime jurídico da habilitação profissional para a docência } \\
\text { na educação pré-escolar e nos ensinos básico e secundário } \\
\text { (revogado). }\end{array}$ \\
\hline D4 (Portugal) & $\begin{array}{l}\text { Decreto-Lei n. }{ }^{\circ} 79 / 2014 \text {, de } 14 \text { de maio - aprova o regime } \\
\text { jurídico da habilitação profissional para a docência na } \\
\text { educação pré-escolar e nos ensinos básico e secundário. }\end{array}$ \\
\hline D5 (Espanha) & $\begin{array}{l}\text { ORDEN ECI/3854/2007, de } 27 \text { de diciembre - por la que se } \\
\text { establecen los requisitos para la verificación de los títulos } \\
\text { universitarios oficiales que habiliten para el ejercicio de la } \\
\text { profesión de Maestro en Educación Infantil. BOE núm. } 312 \text {. }\end{array}$ \\
\hline D6 (Espanha) & $\begin{array}{l}\text { ORDEN ECI/3857/2007, de } 27 \text { de diciembre - por la que se } \\
\text { establecen los requisitos para la verificación de los títulos } \\
\text { universitários oficiales que habiliten para el ejercicio de la } \\
\text { profesión de Maestro en Educación Primaria. BOE núm. } 312 \text {. }\end{array}$ \\
\hline D7 (França) & $\begin{array}{l}\text { NOR: MENE1315928A. Arrêté du 1er juillet } 2013 \text { - relatif au } \\
\text { référentiel des compétences professionnelles des métiers du } \\
\text { professorat et de l'éducation. JORF n0165 du } 18 \text { juillet } 2013 \\
\text { page } 11994 \text {, texte }{ }^{\circ} 4 \text {. }\end{array}$ \\
\hline
\end{tabular}

Fonte: produção do autor.

Em conformidade com a metodologia explanada, operamos com os seguintes elementos de codificação e categorização os dados documentais, a que corresponde à subsequente "unitarização ou transformação do conteúdo em unidades” (Moraes, 1999, p. 4) e descrição em função das respetivas unidades de contexto: 
12

QUADRO 2. Quadro referencial de codificação e categorização dos dados documentais

\begin{tabular}{|c|c|c|c|c|c|}
\hline \multirow{2}{*}{ Documento } & \multirow{2}{*}{$\begin{array}{l}\text { Categorias } \\
\text { temáticas }\end{array}$} & \multirow{2}{*}{ Unidades de Análise } & \multicolumn{3}{|c|}{ Unidades de Contexto } \\
\hline & & & $\mathbf{P +}$ & P- & A \\
\hline & \multirow{8}{*}{$\begin{array}{l}\text { CT1 - Perfil } \\
\text { Socio- } \\
\text { interacional }\end{array}$} & $\begin{array}{l}\text { UA1 - Centralidade na relação/interação } \\
\text { social com os pares }\end{array}$ & & & \\
\hline & & $\begin{array}{l}\text { UA2 - Centralidade na relação/interação } \\
\text { social com os alunos }\end{array}$ & & & \\
\hline & & $\begin{array}{l}\text { UA3 - Centralidade na relação/interação } \\
\text { com os pais/encarregados de educação }\end{array}$ & & & \\
\hline & & $\begin{array}{l}\text { UA4 - Centralidade na relação/interação } \\
\text { com outros atores sociais }\end{array}$ & & & \\
\hline & & UA5 - Centralidade no professor & & & \\
\hline & & UA6 - Centralidade no aluno & & & \\
\hline & & $\begin{array}{l}\text { UA7 - Centralidade na comunidade } \\
\text { educativa }\end{array}$ & & & \\
\hline & & UA8 - Centralidade na sociedade em geral & & & \\
\hline & \multirow{4}{*}{$\begin{array}{l}\text { CT2 - Perfil } \\
\text { Curricular }\end{array}$} & UA9 - Centralidade na gestão curricular & & & \\
\hline & & $\begin{array}{l}\text { UA10 - Centralidade na reprodução } \\
\text { curricular }\end{array}$ & & & \\
\hline & & $\begin{array}{l}\text { UA11 - Centralidade na construção } \\
\text { curricular }\end{array}$ & & & \\
\hline & & UA12 - Centralidade nos saberes escolares & & & \\
\hline & \multirow{3}{*}{$\begin{array}{l}\text { CT3 - Perfil } \\
\text { Pedagógico- } \\
\text { Didático }\end{array}$} & UA13 - Enfoque na polivalência funcional & & & \\
\hline & & UA14 - Enfoque na ação pedagógica & & & \\
\hline & & UA15 - Enfoque na ação didática & & & \\
\hline & \multirow{4}{*}{$\begin{array}{l}\text { CT4 - Perfil } \\
\text { Organizacio- } \\
\text { nal }\end{array}$} & $\begin{array}{l}\text { UA16 - Orientação para a participação } \\
\text { política }\end{array}$ & & & \\
\hline & & $\begin{array}{l}\text { UA17 - Orientação para o envolvimento } \\
\text { focalizado de natureza pedagógica e } \\
\text { didática }\end{array}$ & & & \\
\hline & & $\begin{array}{l}\text { UA18 - Orientação para o envolvimento } \\
\text { focalizado de natureza curricular }\end{array}$ & & & \\
\hline & & $\begin{array}{l}\text { UA19 - Orientação para o controlo/avaliação } \\
\text { da ação profissional }\end{array}$ & & & \\
\hline
\end{tabular}

Fonte: produção do autor. 
Conforme é operado no quadro seguinte, o critério de análise que envolveu as respetivas categorias temáticas (Bardin, 1995) baseou-se numa classificação extraída do corpus textual de cada um dos documentos analisados, mediados, também, pelos referenciais teóricos que mobilizamos para o efeito.

QUADR0 3. Agregação dos domínios de indicadores associados a cada categoria de acordo com os critérios de análise P+, P- e A

\begin{tabular}{|c|c|c|c|c|c|c|c|}
\hline \multirow{2}{*}{ D } & \multirow{2}{*}{ Ст } & \multicolumn{6}{|c|}{ Distribuição (não frequencial) das inferências semânticas (UC) em linha com as UA } \\
\hline & & \multicolumn{2}{|c|}{$P+$ (presença forte) } & \multicolumn{2}{|c|}{ P- (presença fraca) } & \multicolumn{2}{|c|}{ A (ausente) } \\
\hline \multirow{4}{*}{ D1 } & CT1 & \multicolumn{2}{|c|}{ UA2; UA3; UA5; UA6 } & \multicolumn{2}{|c|}{ UA1; UA4; UA7 } & \multicolumn{2}{|c|}{ UA8 } \\
\hline & $\mathrm{CT} 2$ & \multicolumn{2}{|c|}{ UA9; UA10; UA12 } & \multicolumn{2}{|c|}{ UA11 } & & \\
\hline & СT3 & \multicolumn{2}{|c|}{ UA14; UA15 } & & & \multicolumn{2}{|c|}{ UA13 } \\
\hline & CT4 & \multicolumn{2}{|c|}{ UA17; UA18 } & \multicolumn{2}{|c|}{ UA20 } & \multicolumn{2}{|c|}{ UA16; UA19 } \\
\hline \multirow{4}{*}{ D2 } & CT1 & $\begin{array}{l}\text { UA2; UA3; } \\
\text { UA4; UA5; } \\
\text { UA6; UA7* }\end{array}$ & $\begin{array}{l}\text { UA2; } \\
\text { UA6** }\end{array}$ & UA8* & $\begin{array}{l}\text { UA3; } \\
\text { UA5; } \\
\text { UA7** }\end{array}$ & UA $1^{*}$ & $\begin{array}{l}\text { UA } 1 ; \text { UA4; } \\
\text { UA8 }{ }^{* *}\end{array}$ \\
\hline & CT2 & $\begin{array}{l}\text { UA9; UA11; } \\
\text { UA12* }\end{array}$ & $\begin{array}{l}\text { UA9; } \\
\text { UA10; } \\
\text { UA12** }\end{array}$ & UA11* & UA $11^{* *}$ & UA10* & \\
\hline & СT3 & $\begin{array}{l}\text { UA13; UA14; } \\
\text { UA15* }\end{array}$ & $\begin{array}{l}\text { UA14; } \\
\text { UA15** }\end{array}$ & & & & UA13** \\
\hline & CT4 & UA17; UA18* & $\begin{array}{l}\text { UA17; } \\
\text { UA18** }\end{array}$ & & & $\begin{array}{l}\text { UA16; } \\
\text { UA19; } \\
\text { UA20* }\end{array}$ & $\begin{array}{l}\text { UA16; } \\
\text { UA19; } \\
\text { UA20** }\end{array}$ \\
\hline \multirow{4}{*}{ D3 } & CT1 & \multicolumn{2}{|c|}{ UA4; UA5; UA6; UA7 } & \multicolumn{2}{|c|}{ UA2; UA8 } & \multicolumn{2}{|c|}{ UA $1 ;$ UA3 } \\
\hline & $\mathrm{CT} 2$ & \multicolumn{2}{|c|}{ UA9; UA10; UA12 } & \multicolumn{2}{|c|}{ UA11 } & & \\
\hline & СТ3 & \multicolumn{2}{|c|}{ UA14; UA15 } & & & \multicolumn{2}{|c|}{ UA13 } \\
\hline & CT4 & \multicolumn{2}{|c|}{ UA17; UA18 } & \multicolumn{2}{|c|}{ UA20 } & \multicolumn{2}{|c|}{ UA16; UA19 } \\
\hline
\end{tabular}




\begin{tabular}{|c|c|c|c|c|}
\hline \multirow{4}{*}{ D4 } & CT1 & UA4; UA5; UA6; UA7 & UA2; UA8 & UA $1 ;$ UA3 \\
\hline & CT2 & UA9; UA10; UA12 & UA11 & \\
\hline & CT3 & UA14; UA15 & & UA13 \\
\hline & CT4 & UA17; UA18 & UA20 & UA16; UA19 \\
\hline \multirow{4}{*}{ D5 } & CT1 & UA2; UA3; UA6 & UA5; UA7; UA8 & UA1; UA4 \\
\hline & CT2 & UA9; UA10 & UA11; UA12 & \\
\hline & CT3 & UA14; UA15 & & UA13 \\
\hline & CT4 & UA17; UA18 & & UA16; UA19; UA20 \\
\hline \multirow{4}{*}{ D6 } & CT1 & UA2; UA4; UA6; UA8 & UA3; UA5 & UA1; UA7 \\
\hline & CT2 & UA9; UA10 & UA11; UA12 & \\
\hline & CT3 & UA14; UA15 & & UA13 \\
\hline & CT4 & UA17; UA18 & UA20 & UA16; UA19 \\
\hline \multirow{4}{*}{ D7 } & CT1 & $\begin{array}{c}\text { UA1; UA2; UA3; UA4; UA6; } \\
\text { UA7; UA8 }\end{array}$ & UA5 & \\
\hline & $\mathrm{CT} 2$ & UA9; UA10; UA12 & UA11 & \\
\hline & CT3 & UA14; UA15 & & UA13 \\
\hline & CT4 & UA17; UA18; UA20 & & UA16; UA19 \\
\hline
\end{tabular}

Fonte: produção do autor.

* Dados relativos ao perfil de desempenho na área da Educação Pré-Escolar.

** Dados relativos ao perfil de desempenho específico na área do Primeiro Ciclo do Ensino Básico 


\section{As arquiteturas da profissionalização docente na Europa: (des) articulações na normalização dos perfis de formação em perspetiva comparada}

No que concerne ao perfil sociointeracional (CT1), face às duas centralidades mais constantes no quadro semântico dos documentos analisados (UA2 - Centralidade na relação/interação social com os alunos e UA6 - Centralidade na relação pedagógica com os alunos), emerge a assunção de que a perspetiva dos estudos há muito desenvolvidos em torno das interações professor-aluno, com enfoque, quase exclusivo, no professor deixa de ter relevância hermenêutica na nossa análise. Semanticamente, o aluno surge com destaque semelhante ao que é dado ao professor. Ao mesmo tempo, os discursos ou narrativas oficiais que configuram o espectro da profissionalidade docente, sustentado na arquitetura normativa dos respetivos perfis de desempenho, faz-nos considerar que se a performance do aluno tenderá, por pronúncio normativo, a condicionar o desempenho do professor, sendo que o inverso também acontece.

O enfoque dado àquelas duas centralidades discursivas representa um claro reconhecimento formal da influência mútua que ocorre entre a ação dos alunos e o desempenho que se espera dos professores. Pelo mesmo alinhamento, faz-se notar uma semântica discursiva especialmente atenta ao controlo dos estímulos dos professores e dos alunos, estimulada pela ideia, ainda que implícita e conjugada por outros vocábulos (ex.: ensino de qualidade, melhores aprendizagens) de ensinoaprendizagem sem falhas. Isto quer dizer que se estabelece, formalmente, uma relação causal mutualista entre o professor competente e o aluno com bom desempenho escolar, que a perceção que nos é deixada nos diferentes discursos analisados é que ambos estes atores desenvolvem uma ação suscetível de ser aperfeiçoada em função da ação do outro (cf. Sidman, 1985). O que antes era considerado uma assimetria de domínio de saberes dá lugar a uma simetria de relacionamento e interação social de feição pedagógica e didática (cf. Gil, 1993).

Da centralidade dada à relação/interação com os pais/ encarregados de educação (UA3), mantém-se, absolutamente transversal nos discursos analisados, a ideia pré-formatada de que a relação otimizada estabelecida entre a escola e os pais/encarregados de educação é potenciadora do sucesso educativo dos alunos, corroborando a ideia de Philippe Perrenoud et al. (2001) na conexão forte que faz entre o destino das famílias e o processo de escolarização contemporânea.

Ainda no quadro da CT1 (perfil sociointeracional), atendemos, particularmente, à centralidade dada à relação/interação social com 
os pares (UA1). Deparamo-nos com uma semântica discursiva, em qualquer um dos documentos analisados, em que a importância das interações entre professores para o seu próprio desenvolvimento e para o desenvolvimento dos processos escolares não abunda, não havendo qualquer preocupação em lhe dar um especial destaque, ainda que se reconheça, por outras vias interpretativas, a sua importância.

Não obstante, desenvolvendo a nossa hermenêutica segundo um alinhamento mais crítico do papel do professor e das suas interações relacionais com os seus pares, diríamos que se ausenta dos discursos e narrativas oficiais que normalizam o perfil profissional dos professores uma perspetiva sociocultural construtivista, na base do pressuposto da participação (política) ativa suscetível de envolver a perceções culturais coletivas sobre os processos escolares. Per se, tal alusão implicaria debate e negociação, desde logo, sobre aqueles processos e respetivos objetivos dos diferentes grupos e sujeitos em interação, ainda que sob a inevitabilidade de lidar com cenários matizados ora por convergência, ora por divergência, num cenário mais propício à educação política dos professores e educadores (Rangel \& Petry, 2005).

Diríamos que, interpretativamente, esta linha normalizadora apresenta-se pouco ou nada suscetível a uma interação entre pares orientada para a negociação dos atos educacionais, dado que, tal como são apresentados em outros suportes legislativos, os objetivos da educação não se apresentam como substancialmente negociáveis, debatíveis, mas, tão só, executáveis. Neste caso, o apelo à participação, indo para além da mera interação normalizada entre pares, alinhar-se-á, muito mais, com interseções ao nível dos planos de regulação do trabalho desenvolvido pelos professores, incluindo necessidades de investigação, avaliação e formação realizadas a partir de dentro da escola (cf. Nóvoa, 2001).

Relativamente ao perfil de agente curricular (CT2), destacamos uma especial centralidade em torno da gestão curricular (UA9) e da reprodução curricular (UA10), em cujos discursos analisados faz-se notar com grande evidência semântica a normalização dos perfis de desempenho profissional dos professores na base da normalização das políticas enquadradoras do currículo formal e oficialmente prescrito. Neste caso, assiste-se à produção de narrativas oficiais que aludem, maioritariamente, ao papel da escola e dos professores, inserindoos no vulto ideológico das competências profissionais e num claro apelo, formalmente instituído, a um processo de profissionalização que vincula os professores a mecanismos de socialização de uma profissionalidade que, per se, determina o modo como os professores se relacionam com o conceito e com a gestão do currículo escolar, 
pelo que aqueles veem a sua ação alinhada com uma forma (oficial) sobre o que ensinar, o como organizar a aprendizagem e o como avaliar os seus resultados, numa clara alusão a uma agenda ideológica alinhada pelos paradigmas socioculturais industrial e racional, conectado ao paradigma tecnológico da educação (Bertrand \& Valois, 1994).

Mesmo com a centralidade que é dada ao aluno, por consequência da ação do professor focalizada numa interação mais robustecida com os alunos e com os pais/encarregados de educação, tal não parece significar que se tenham abandonado, em definitivo, modos de organização instrumental do currículo escolar e procedimentos curriculares tecnicistas.

$\mathrm{Na}$ verdade, é suscitada uma narrativa harmonizada em torno de uma hibridez curricular (Young, 2010), em que a organização do currículo assenta numa dialética desgravitada entre a uma perspetiva conservadora e uma visão modernista, cuja tónica discursiva tende a assentar no argumento da interdisciplinaridade mas que, na prática, se limita ao que é considerado no processo de internalização curricular, matizado pela institucionalização de algumas medidas tipificadas por Michael Young (2010) como sendo externalistas.

Com efeito, ao reconhecer a inadequação de um currículo construído em função apenas do aluno padrão, os legisladores desenvolvem uma narrativa díptica conforme a uma perceção, por parte do professor, híbrida dos currículos nacionais, prescrevendo a obrigatoriedade de procedimentos de gestão flexível assente em princípios de integração e territorialização locais ressemantizados pelo apelo a procedimentos de orientação humanista de raiz social e democrática que se expressam em práticas pedagógicas centradas no aluno e nas suas singularidades.

Não obstante, o padrão discursivo instituído pelas narrativas analisadas não nos garante uma perspetivação histórico-social do currículo como autêntica descentralização da organização e gestão do currículo.

É comum aos discursos oficiais analisados a preocupação em manter o perfil profissional dos professores no domínio das competências curriculares - e, consequentemente, pedagógicas e didáticas - no sentido de garantir as aprendizagens que devem ser comuns" (Roldão, 2015, p. 10), ou de concretizar "um conjunto mínimo de aprendizagens básicas pela totalidade do universo discente" (Sebastião \& Correia, 2007, p. 109) que permita "o acesso ao conhecimento, às competências e aos processos que vão permitir a igualdade social em termos de conhecimento, que não é sinónimo de conteúdos puros e duros" (Roldão, 2015, p. 10). 
Os perfis de competências que consagram o professor subsidiam o seu próprio recentramento como agente curricular, substituindo o seu papel numa organização curricular baseada no ensino de conteúdos disciplinares, de estrutura rígida e uniforme (Formosinho, 2007), por um enfoque na gestão e execução curricular centradas na realização de competências-chave, em resultados de aprendizagem com base nas abordagens curriculares transversais, com um claro apelo à liderança da gestão curricular centrada na escola, auxiliada por uma "assessoria curricular" (Bolívar, 2012, p. 170), com o objetivo de apoiar os professores no processo de gestão externalista e local do currículo.

Da análise feita no âmbito do perfil pedagógico-didático (CT3), o duplo enfoque na ação pedagógica (UA14) e na ação didática (UA15), começamos por retomar uma discussão já antes desenvolvida por nós (Ramalho, 2015), a propósito da performatividade pedagógica e didática de feição técnico implementalista e a sua conexão ao corpus legislativo da formação de educadores e professores. Inscrevemos as nossas alegações na linha de problematização do contexto em que se dá uma intensificação da normalização da formação de professores, circunstanciado pelos últimos exercícios legislativos ocorridos e, ainda, pela adesão ao Processo de Bolonha.

Assim é balizada a formação inicial de professores pela fronteira ideológica da noção de competência performativa (Chaui, 2014) de feição curricular, pedagógica e didática, segundo uma "relação performatizada", burocraticamente estabelecida entre o professor, o aluno e o Sistema (Icle \& Lulkin, 2013, p. 117).

$\mathrm{Na}$ senda daquele essencialismo de feição comportamentalista do professor pedagogo e didático, reforça-se a capacidade de o Sistema "verificar o domínio de conhecimentos e capacidades fundamentais para o exercício da função docente" (n. 8 do art. ${ }^{\circ} 22$. $^{\circ}$ do DecretoLei n. ${ }^{\circ} 146 / 2013$ de 22 de outubro):

\footnotetext{
O enfoque do papel da Didática a partir dos pressupostos da Pedagogia Tecnicista procurou desenvolver uma alternativa não-psicológica, situando-se no âmbito geral da Tecnologia Educacional, tendo como preocupação básica a eficiência e a eficácia do processo de ensino. [..] o processo é que define o que professores e alunos devem fazer, quando e como farão. [..] Enfim, a Didática é concebida como estratégia para o alcance dos produtos previstos para o processo ensinoaprendizagem (Veiga, 1989, p. 60-61).
}

De todo modo, vincula-se a formação pedagógica e didática do futuro professor a uma efetivação profissional técnico-burocrática de índole racionalista e absoluta, que determina heteronomamente as dimensões a que aquela realização profissional deverá estar conectada. 
Eis que, à luz dos discursos oficiais analisados, a didática emerge como disciplina essencial na formação do professor, assistindo-se a uma espécie de eclosão revigorada da didática (Pimenta et al., 2013), cuja ressignificação reafirma os processos de ensino-aprendizagem repletos de interações entre atores comprometidos com a mesma causa emanada do Sistema.

Realça-se, no caso português, um reforço dos enfoques na ação pedagógica (UA14) e na ação didática (UA15), em que a revogação do Decreto-Lei n. ${ }^{\circ} 43 / 2007$, de 22 de fevereiro pelo Decreto-Lei n. ${ }^{\circ}$ $79 / 2014$, de 14 de maio, veio resultar num robustecimento dessas componentes ao nível das estruturas curriculares, especialmente no caso dos ciclos de estudos conducentes ao grau de mestre, pelo que, em termos evolutivos, se assiste a um reforço substancial das unidades de crédito atribuídas às didáticas específicas e à prática de ensino supervisionada. Faz-se notar, ainda, um incremento na centralidade na formação da área da docência (Perfil Curricular [CT2] - saberes escolares [UA12]), pelo que, por exemplo, no caso particular da estrutura curricular da Educação Pré-Escolar e da estrutura curricular de Professor do Ensino B ásico do 1. 'Ciclo (mestrados), o primeiro diploma não previa a sua lecionação, passando a ser prevista no quadro regulamentar do segundo diploma legal.

Quanto ao perfil organizacional (CT4), e atendendo a que nos referimos à organização, administração, direção e gestão das escolas, é absolutamente necessário que circunstanciemos tais vocábulos no seu exato propósito com que se aplicam ao funcionamento da escola, à ação dos professores e, decorrentemente, à sua preparação e treino profissionais. Pelas centralidades semânticas dos discursos analisados, ao destacar a orientação para o envolvimento focalizado de natureza pedagógica e didática (UA17) e a orientação para o envolvimento focalizado de natureza curricular (UA18).

Neste caso, a essência discursiva do funcionamento da escola, da ação/envolvimento dos professores e da sua formação, à luz dos respectivos perfis de desempenho profissional analisados, continua a ser balizada mais pelo horizonte gestionário, e menos pelo incremento de práticas (auto)diretivas e autonômicas mais efetivas.

Esse mesmo horizonte gestionário, sendo mais sofisticado e complexo, não parece ter-se distanciado dos velhos domínios em que sempre ocorreu: a esfera curricular e, mais especificamente, o domínio da pedagogia e didática. Ou seja, um horizonte gestionário de feição tecnicista, subsisiado pelo retorno do primado da pedagogia de espectro europeísta. Neste caso, percebe-se o efeito do pensamento 
pedagógico vincular os raciocínios políticos, coincidente com o primado da regulação centro administrativa dos perfis profissionais dos professores e educadores da escola pública. Neste caso, a formação de professores e educadores parece vincular-se aos preceitos da "pedagogia coletiva" que tem obrigado à "reinvenção" da classe docente na base de uma cultura da homogeneidade (das normas, dos espaços, processos de gestão escolar, do currículo, da avaliação, dos tempos, dos alunos, dos professores). Neste caso, a nossa análise faz notar que as expressões organização e gestão, parca, mas, sutilmente, utilizadas, induzem-nos a interpretar a escola como uma organização especialmente vocacionada para albergar professores-gestores curriculares, pedagógicos e didáticos, sendo compreendida como uma unidade social, que reúne atores em interação programada, por meio de estruturas e processos organizativos normalizados, para se alcançar os objetivos do Sistema, na base da divisão do trabalho dos docentes.

Quando antes nos referimos à eclosão revigorada da didática no quadro dos vários perfis de desempenho dos professores analisados, com naturais consequências na arquitetura dos currículos de formação inicial, damo-nos conta que as centralidades semânticas detetadas na nossa análise provocam um relativo, mas considerável, desvio da formação dos professores de matérias destinadas à compreensão do Sistema (incluindo a escola e a estrutura/estatuto profissional).

Ou seja, o realce semântico aqui convocado parece justificar a alusão a um Sistema que se alimenta por atores perfilados na senda de uma ideologia de competências imutáveis, consolidando a ideia de uma disciplina profissional vinculada a uma estrutura do Sistema, que se confunde com a anatomia dos processos de ensino-aprendizagem - estruturas e órgãos que os realizam - e com a fisiologia de uma profissionalidade docente - o modo como os professores devem, formalmente, atuar em tais processos (cf. Saviani, 1987), segundo a nuance da alienação profissional normalizada.

Com efeito, ocorre-nos dizer que a disciplina profissional do professor parece surgir (re)afirmada como o epicentro da estrutura organizacional da escola e do Sistema, estando, como exemplifica esta nossa análise, resguardada por meio de textos legislativos, que institucionalizam a organização do trabalho curricular, pedagógico e didático, com um claro predomínio da gestão de recursos e das interações escolares.

Das ausências mais relevantes, destacamos a orientação para a participação política (UA16), precisamente no sentido em que decorre da linha interpretativa que desenvolvemos no ponto anterior, 
fazendo notar que, da ligação que se faz entre a normalização dos perfis profissionais e as arquiteturas dos currículos de formação inicial dos professores e educadores, os diferentes legisladores não suscitam quaisquer preocupações com a sua formação política.

Mesmo aceitando que os legisladores admitem a prerrogativa da multidimensionalidade dos processos curriculares, pedagógicos e didáticos no desenho que fazem dos respectivos perfis de desempenho, fazem-no acentuando os compromissos técnicos e gestionários, mas desvinculando esses mesmos perfis dos compromissos políticos ou, simplesmente, da ação política dos professores.

Neste mesmo registo analítico e interpretativo, é difícil perspetivar - no discurso, mas não, necessariamente, na prática - a dimensão política inerente às arquiteturas dos perfis de desempenho e de habilitações para a docência (cf. Rangel, 2003).

$\mathrm{Na}$ verdade, alguns dos ingredientes da participação política são discursivamente expostos pelos legisladores (participação, envolvimento, decisão, comprometimento, o agir coletivo etc.). Contudo, o seu grau de instrumentalização é absolutamente desviante do verdadeiro ethos político da ação dos professores da única fonte do poder político: a ação comunicativa associada ao não impedimento da liberdade de agir e falar (Habermas, 1999).

Assiste-se, neste caso, a uma colisão de posições: por um lado, tal como antes observamos, os legisladores preconizam arquiteturas de perfis de desempenho especialmente resistentes ao erro curricular, pedagógico e didático, mostrando a flexibilidade suficiente para que os principais protagonistas (alunos e professores) se adaptem continuamente aos processos, tornando o Sistema impermeável a eventuais falhas das periferias; por outro lado, à luz dos perfis de desempenho docente em análise, não é evidenciada uma semântica que, discursivamente, promova o pensamento educacional, organizacional, curricular e pedagógico crítico, reflexivo e dialético, por exemplo, entre pares. A par disso, sobrevém o argumento de que as indagações, as dúvidas, as divergências, a argumentação livre, a plurirracionalização das falhas, a decisão e o agir coletivos são prerrogativas próprias da esfera política (da escola e do Sistema) e, propriamente, da participação política autêntica, na qual a teoria política deveria intervir.

\section{DISCUSSÃO E CONCLUSÃO}

A primeira das nossas conclusões, decorrendo de um primeiro momento da nossa análise, leva-nos a envolver os mecanismos de 
normalização dos perfis de desempenho e da habilitação para a docência da zona de Bolonha na agenda mais recente da regulação das políticas públicas da educação e formação de profissionais da docência. Ou seja, o processo de Bolonha vem cumprir com um propósito de regulação transnacional das competências dos professores e educadores. Assim também se vulgariza um efeito regulatório fortemente conectado ao vulto ideológico da New Public Management, a propósito do qual se destaca o vigor da CE.

O mercantilista de Bolonha, a que antes nos referimos, afirma-se e legitima-se com recurso à poderosa retórica da garantia da qualidade de um sistema europeu de ensino superior que, erigido de uma lógica claramente empresarial, sob a ação implementalista das diferentes agências nacionais de uma política de accountability, traduzida num amplo e consistente processo de meta-acreditação de standards, inscrevem, de forma muito vigorosa, a formação dos professores e educadores na linha da "obrigação de resultados", enquanto nova cultura mercantil e utilitária para os quais a classe docente se tem vindo a constituir no principal "doador".

Eis que reemerge, com grande robustez, o primado do desempenho previsivel, controlável e avaliável, conduzindo a um recentramento do professor/educador enquanto figura-chave, ou, metaforicamente configurado como a black box do Sistema.

$\mathrm{Na}$ linha paradigmática da aprendizagem ao longo da vida, as competências de feição empresarial ganham especial destaque, enquanto pedras basilares da europeidade, pelo que, a um certo nível, são associadas prerrogativas à formação de professores e educadores comuns às das outras profissões, de forma absolutamente indiferenciada.

Congruentemente, uma das maiores preocupações que se fazem notar ao nível de todas essas orientações, conjuga a necessidade de desenvolver um conjunto de habilidades básicas (alfabetização, numeracia, língua materna, línguas estrangeiras, ciência e habilidades digitais), com a necessidade de ser desenvolvidas habilidades transversais (capacidade de aprender, ter iniciativa etc.) e de habilidades empresariais, em que ganha especial destaque a comunicação efetiva entre o mercado de trabalho e o setor de educação e treinamento. Nesse enquadramento, a conjugação entre a Declaração de Bolonha com o argumento paradigmático da aprendizagem ao longo da vida, transforma-se num poderoso utensílio para a consolidação da estratégia de unificação intermercantilista da EU.

Propriamente, sobre o modo como as arquiteturas de formação de professores de diferentes países da zona Bolonha (Espanha, França e Portugal) se (des)articulam com quadros de competências definidos 
em linha com a normalização dos perfis de desempenho profissional, destacamos algumas das centralidades mais consistentes: i) da análise semântica que nos foi possível fazer, o aluno surge com destaque semelhante ao que é dado ao professor, fazendo-nos considerar que, se a performance do aluno tender, por prescrição normativa, a condicionar o desempenho do professor, o inverso também acontece, segundo a prerrogativa de um ensino-aprendizagem sem falhas; ii) um outro destaque semântico decorre da importância dada ao perfil de agente curricular do professor/educador, vinculando-os a mecanismos de profissionalização que determinam o modo como os professores/ educadores se relacionam com o conceito e com a gestão do currículo escolar, pelo que aqueles veem a sua ação alinhada com uma forma (oficial) sobre o que ensinar, o como organizar a aprendizagem e o como avaliar os seus resultados na linha ideológica dos paradigmas socioculturais industrial e racional, conectada ao paradigma tecnológico da educação, concretizando um perfil de competências almejado na senda de um certo essencialismo de feição comportamentalista do professor/educador curricular, pedagogo e didático.

Pelas centralidades semânticas dos discursos analisados, ao destacar a orientação para o envolvimento focalizado de natureza pedagógica e didática e a orientação para o envolvimento focalizado de natureza curricular, perde-se, ainda que ponderando apenas o limite macrodiscursivo, a relevância semântica dada a práticas (auto)diretivas mais efetivas, assistindo-se a um manifesto desvio da formação dos professores/educadores de matérias destinadas à compreensão do Sistema (incluindo a escola, a estrutura e o estatuto socioprofissional).

Assim parece ser consolidada a ideia de uma disciplina profissional vinculada a uma estrutura do Sistema, que se confunde com a anatomia dos processos de ensino-aprendizagem - atores, estruturas e órgãos que os realizam - e com a fisiologia de uma profissionalidade docente - o modo como os professores devem, formalmente, atuar em tais processos conjugados num cenário pouco propício à educação política dos professores e educadores.

\section{REFERÊNCIAS}

ALMEIDA, J. ; PINTO, J. A investigação em Ciências Sociais. Lisboa: Editorial Presença, 1995.

ANTUNES, F. (2004). Políticas Educativas Nacionais e Globalização. Novas Instituições e Processos Educativos. Braga: Centro de Investigação em Educação, Universidade do Minho, 2004. 
ANTUNES, F. Regulação supranacional e governação da educação: dimensões europeias. Administração Educacional, (5), 6-19, 2005.

ANTUNES, F. A nova ordem educativa mundial e a União Europeia: a formação de professores dos Princípios Comuns ao ângulo Português. Perspectiva, 25(2), 425-468, 2007.

Bardin, L. Análise de conteúdo. Lisboa: Edições 70, 1995. (Trabalho original em francês, publicado em 1977).

BERTRAND, Y.; VALOIS, P. Paradigmas educacionais: escola e sociedades. Lisboa: Instituto Piaget, 1994.

BOLÍVAR, A. Melhorar os processos e os resultados educativos. O que nos ensina a investigação. Vila Nova de Gaia: Fundação Manuel Leão, 2012.

Chaui, M. A ideologia da competência. São Paulo: Autêntica Editora, 2014.

EUROPEAN COMISSION (n.d.). Common European Principles for Teacher Competences and Qualifications. Brussels: European Comission. Disponível em: http://www.pef.uni-lj. si/bologna/dokumenti/eu-common-principles.pdf. Acessado em: 12 de fevereiro de 2018.

COMISSÃO EUROPEIA. Educação e Formação na Europa: Sistemas Diferentes, Objectivos Comuns para 2010. Luxemburgo: Serviço das Publicações Oficiais das Comunidades Europeias, 2002.

COMISSÃO EUROPEIA (2007). Competências Essenciais para a Aprendizagem ao Longo da Vida - Quadro de Referência Europeu. Luxemburgo: Serviço das Publicações Oficiais das Comunidades Europeias. Luxemburgo: Serviço das Publicações Oficiais das Comunidades Europeias. Disponível em: https://www.dges.gov.pt/sites/default/files/brochura_qeq.pdf. Acessado em: em 12 de fevereiro de 2018.

COMISSÃO EUROPEIA (2012). Comunicação da Comissão ao Parlamento Europeu, ao Conselho, ao Comité Económico e Social Europeu e ao Comité Das Regiões: Repensar a Educação - Investir nas competências para melhores resultados socioeconómicos. Estrasburgo: Comissão Europeia. Disponível em: file:///C:/Users/asus/Downloads/ COM_2012_669_PT_ACTE_f.pdf. Acessado em: 12 de fevereiro de 2018.

COMISIÓN EUROPEA (2015). La profesión docente en Europa: Prácticas, percepciones y políticas. Brussels: Agencia Ejecutiva en el ámbito Educativo, Audiovisual y Cultural. Disponível em: file:///C:/Users/asus/Downloads/EC0115389ESN.es.pdf. Acessado em: em 12 de fevereiro de 2018).

COMISSÃO EUROPEIA (2016). Comunicação da Comissão ao Parlamento Europeu, ao Conselho, ao Comité Económico e Social Europeu a ao Comité das Regiões - uma nova agenda de competências para a Europa: Trabalhar em conjunto para reforçar o capital humano, a empregabilidade e a competitividade. Bruxelas: Comissão Europeia. Disponível em: http:/ / eur-lex.europa.eu/legal-content/PT/TXT/PDF/?uri=CELEX:52016DC0381\&from=PT. Acessado em: 12 de fevereiro de 2018.

COMUNIDADES EUROPEIAS. Quadro Europeu de Qualificações para a aprendizagem ao longo da vida (QEQ). Luxemburgo: Serviço das Publicações Oficiais das Comunidades, 2009. 
CONTRERAS, J. A autonomia de professores. São Paulo: Cortez, 2012.

CORREIA, J. Sociologia da educação tecnológica. Lisboa: Universidade Aberta, 1996.

CORREIA, J.; MATOS, M. (2001). Da crise da escola ao escolocentrismo. In STOER S. R.; CORTESÃO, L.; CORREIA J. A. (orgs.). Transnacionalização da educação. Da crise da educação à "educação" da crise. Porto: Edições Afrontamento, s. d. p.91-117

DALE, R. Globalization and education: demonstrating a 'common world educational culture' or locating a 'globally structured educational agenda'? Educational Theory, 50(4), 427-448, 2000.

DECLARAÇÃO DE BOLONHA. Declaração conjunta dos ministros da educação europeus, assinada em Bolonha. (19. Junho.1999). Disponível em: http://media.ehea.info/ file/Ministerial_conferences/05/3/1999_Bologna_Declaration_Portuguese_553053.pdf. Acessado em: 12 de fevereiro de 2018.

DECRETO-LEI No 240/2001, de 30 de agosto - Perfil geral de desempenho profissional do educador de infância e dos professores dos ensinos básico e secundário. Diário da República, I Série A. Lisboa.

DECRETO-LEI n ${ }^{\circ}$ 241/2001, de 30 de agosto - Perfis específicos de desempenho profissional do educador de infância e do professor do $1 .^{\circ}$ ciclo do ensino básico. Diário da República, I Série A. Lisboa.

DECRETO-LEI N. ${ }^{\circ}$ 43/2007, 22 de fevereiro - Regime Jurídico de Habilitação Profissional para a Docência. Diário da República, I Série. Lisboa.

DECRETO-LEI N. ${ }^{\circ}$ 369/2007, de 5 de novembro - Institui a Agência de Avaliação e Acreditação do Ensino Superior. Diário da República, I Série. Lisboa.

DECRETO-LEI N. ${ }^{\circ}$ 146/2013 de 22 de outubro - Alteração do Estatuto da Carreira dos Educadores de Infância e dos Professores dos Ensinos Básico e Secundário. Diário da República, I Série. Lisboa.

DECRETO-LEI N. ${ }^{\circ}$ 79/2014 de 14 de maio - Regime jurídico da habilitação profissional para a docência na educação pré-escolar e nos ensinos básico e secundário. Diário da República, I Série. Lisboa.

DUBAR, C. La crise des identités. L'interprétation d'une mutation. Paris: PUF, 2000.

EUROPEAN ASSOCIATION FOR QUALITY ASSURANCE IN HIGHER EDUCATION (ENQA) (2015). Standards and Guidelines for Quality Assurance in the European Higher Education Area. Brussels: EURASHE. Disponível em: http://www.enqa. eu/wp-content/uploads/2015/11/ESG_2015.pdf. Acessado em: 12 de fevereiro de 2018.

EUROPEAN COMMISSION (EC) (2000). A Memorandum for Lifelong Learning. Disponível em: http://arhiv.acs.si/dokumenti/Memorandum_on_Lifelong_Learning.pdf. Acessado em: 12 de fevereiro de 2018.

EUROPEAN COMISSION (2018). Proposal for a Council Recommendation on Key Competences for Lifelong Learning. Brussels: European Comission. Disponível em: 
https://ec.europa.eu/education/sites/education/files/recommendation-key-competenceslifelong-learning.pdf. Acessado em: 12 de fevereiro de 2018.

FORMOSINHO, J. O Currículo Uniforme Pronto-a-vestir de tamanho único. Lisboa: Edições Pedago, 2007.

GARCÍA MANJÓN, J. (Coord.) (2009). Hacia el espacio europeo de educación superior. El reto de la adaptación de la Universidad a Bolonia. La Coruña: Netbiblo, 2006.

GIL, M. Interação social na escola: professor e aluno construindo o processo ensinoaprendizagem. Temas de Psicologia (3), 29-38, 1993.

HABERMAS, J. Teoría de la accíon comunicativa. Madrid: Taurus, 1999.

HARGREAVES, A. et al. Aprendendo a mudar: o ensino para além dos conteúdos e da padronização. Porto Alegre: Artmed, 2002.

ICLE, G.; LULKIN, S. (2013). Didática buffa: uma crítica à interpretação numa performance da profanação. Currículo sem Fronteiras, 13(2), 116-128. Disponível em: http://www. curriculosemfronteiras.org/ vol13iss1articles/icle-lulkin.htm. Acessado em: 12 de fevereiro de 2018.

LAVAL, C. Le Nouvel ordre éducativ mondial. OMC, Banque Mondiale, OCDE, Comission européenne. Nouveaux Regards. Paris: Regards/Syllepse, 2002.

LESSARD, C. Universidade e a formação profissional dos docentes: novos questionamentos. Educação \& Sociedade, 27(94), 201-227, 2002.

LIMA, 1.; AZEVEDO, M.; CATANI, A. O Processo de Bolonha, a Avaliação da Educação Superior e algumas Considerações sobre a Universidade Nova. Avaliação, 13(1), 7-36, 2008.

MAROY, C. Vers une régulation pós-buroeaucratique des systèmes d'enseignement en Europe? Les Cahiers de Recherche en Education et Formation, (49), 1-30, 2005.

NOR: MENE1315928A. Arrêté du 1er juillet 2013 - Relatif au référentiel des compétences professionnelles des métiers du professorat et de l'éducation. JORF $\mathrm{n}^{\circ} 0165$ du 18 juillet 2013 page 11994, texte n 4. Paris. Disponível em: https://www. legifrance.gouv.fr/eli/arrete/2013/7/1/MENE1315928A/jo/texte. Acessado em: 26 de janeiro de 2018.

NÓVOA, A. Os professores. Quem são? Donde vêm? Para onde vão? In STOER, S. R. (Org.). Educação, ciências sociais e realidade portuguesa: uma abordagem pluridisciplinar. Porto: Edições Afrontamento, 1991. p. 59-126

NÓVOA, A. Professor se forma na escola. Nova escola, (142), 13-15, 2001.

ORDEN ECI/3854/2007, de 27 de diciembre - Por la que se establecen los requisitos para la verificación de los títulos universitarios oficiales que habiliten para el ejercicio de la profesión de Maestro en Educación Infantil. BOE núm. 312. Madrid. Disponível em: https:// www.mecd.gob.es/educacion-mecd/areas-educacion/profesorado/no-universitarios/ formacion/formacion-inicial.html. Acessado em: 26 de janeiro de 2018. 
ORDEN ECI/3857/2007, de 27 de diciembre - Por la que se establecen los requisitos para la verificación de los títulos universitários oficiales que habiliten para el ejercicio de la profesión de Maestro en Educación Primaria. BOE núm. 312. Madrid. Disponível em: https:// www.mecd.gob.es/educacion-mecd/areas-educacion/profesorado/no-universitarios/ formacion/formacion-inicial.html. Acessado em: 26 de janeiro de 2018.

PIMENTA, S. et al. A construção da didática no GT Didática - análise de seus referenciais. Revista Brasileira de Educação, 18(52), 143-162, 2013.

PERRENOUD, Ph. et al. Formando professores profissionais. Quais estratégias? Quais competências? Porto Alegre: Artmed, 2001.

PIOTET, F. La révolution des métiers. Paris: PUF, 2002.

PONTE, J. O processo de Bolonha e a formação inicial de professores em Portugal. In SERRALHEIRO, J. P. (org.). O processo de Bolonha e a formação dos educadores e professores portugueses. Porto: Profedições, 2005. p. 63-73.

RAMALHO, H. Sinuosidades da Formação Pedagógica e Didática dos Professores: entre a cultura da performatividade de feição técnico implementalista e o desafio da formação investigativo reflexiva. Saber \& Educar, (20), 254-263, 2015.

RANGEL, M. Representações e reflexões sobre o “bom professor”. Petrópolis: Vozes, 2003.

RANGEL, M.; PETRY, P. Educação política de professores: conceitos e importância. Educação - RS, 2(56), 352 - 360, 2005.

ROBERTSON, S. Re-imagining and rescripting the future of education: global knowledge economy discourses and the challenge to education systems. Comparative Education, 41(2), 151-170, 2005.

ROLDÃO, M. Romper os pilares da homogeneidade. O Pátio, Revista bimestral da EPM-CELP, (94), 9-11, 2015.

SANTOS, S. M. Análise comparativa dos processos europeus para a avaliação e certificação de sistemas internos de garantia da qualidade. Lisboa: A3ES, n. 1, 2011.

SAVIANI, D. Educação: do senso comum à consciência filosófica. Campinas (SP): Autores Associados, 1987.

SEBASTIÃO, J.; CORREIA, S. A democratização do Ensino em Portugal. In: VIEGAS, José Manuel Leite; CARREIRAS, Helena; MALAMUD, Andrés (orgs.). Instituições e Política. Portugal no Contexto Europeu. Lisboa: Celta Editora, 2007. p-107-136.

SERRALHEIRO, J. (org.). O processo de Bolonha e a formação dos educadores e professores portugueses. Porto: Profedições, 2005.

SIDMAN, M. Aprendizagem sem-erros e a sua importância para o ensino do deficiente mental. Psicologia, 11(3), 1-15 1985.

SCOTT, P. Going beyond Bologna: issues and themes. In CURAJ A.; SCOTT, P.; L. VLASCEANU, L.; WILSON, L. (Eds.). European higher education at the crossroads between the Bologna process and national reforms (pp. 1-15). Londres: Springer, 2012. 
SIMÃO, J. V; SANTOS, S. M.; COSTA, A. A. (2005). Ambição para a excelência: a oportunidade de Bolonha. Lisboa: Gradiva, 2005.

VEIGA, I. A prática pedagógica do professor de didática. Campinas: Papirus, 1989.

YOUNG, M. Conhecimento e currículo: do socioconstrutivismo ao realismo social na sociologia da educação. Porto: Porto Editora, 2010.

\section{NOTAS}

1 cf. http://www.fam.ulusiada.pt/downloads/bolonha/docs02_declaracaobolonha.pdf

2 no caso português, temos, atualmente, a agência de avaliação e acreditação do ensino superior, a3es (cf. decreto-lei n. ${ }^{\circ}$ 369/2007, de 5 de novembro).

3 cf. https://ec.europa.eu/eures/public/pt/homepage

4 cf. http://eur-lex.europa.eu/summary/glossary/open_method_coordination. htmllocale $=$ pt

5 cf. http://www.drapc.min-agricultura.pt/base/geral/files/estrategia_lisboa.pdf

6 cf. http://www.ehea.info/

Submetido: $12 / 06 / 2018$

Aprovado: 15/10/2018

Contato:

Escola Superior de Educação de Viseu

Rua Maximiano Aragão

VISEU|PORTUGAL

3504-501 